11

\title{
Frontal Analysis Continuous Capillary Electrophoresis for Protein-Polyelectrolyte Binding Studies
}

\author{
Emek Seyrek, Toshiaki Hattori, and Paul L. Dubin
}

\begin{abstract}
Summary
A novel technique, frontal analysis continuous capillary electrophoresis (FACCE), has been described as an effective way to study protein-polyelectrolyte binding. FACCE involves continuous sampling, integrating sample injection and separation into one process that provides advantages over conventional frontal chromatography. The method provides rapid and precise determination of binding isotherms, and allows for quantitative binding analysis in terms of binding constant and the binding-site size by considering the protein as the ligand and allowing the polyelectrolyte to bind to a number of proteins with variable levels of cooperativity. FACCE is particularly suitable for binding systems involving rapid binding kinetics because it allows for the determination of the concentrations of free or bound ligands under conditions that avoid perturbation of the binding equilibrium. This chapter focuses on studies of the binding of bovine serum albumin (BSA) to heparin using FACCE. These investigations are demonstrated within the context of this chapter as representative of a model protein-polyelectrolyte system from which extensions to other systems can be made.
\end{abstract}

\section{Key Words}

Binding constant; binding isotherm; binding site size; bovine serum albumin; capillary electrophoresis; heparin; patch binding; protein-polyelectrolyte.

\section{Introduction}

Capillary electrophoresis (CE) has been used increasingly for protein-ligand binding studies, such as the association of proteins with drugs (1-4), inorganic ions $(5,6)$, sugars $(7)$ and micelles $(8,9)$. The CE techniques applied involve either the measurement of mobility or the determination of the concentrations of free or bound ligand $(\mathbf{1 - 3 , 1 0})$. The main problems observed in binding studies based on those $\mathrm{CE}$ techniques are: (1) the difficulty in calibration for quan-

From: Methods in Molecular Biology, vol. 276: Capillary Electrophoresis of Proteins and Peptides Edited by: M. A. Strege and A. L. Lagu (c) Humana Press Inc., Totowa, NJ 
titative studies, and (2) the perturbation of the binding equilibria caused by the dynamic behavior of the systems under study. A novel method that addresses these problems, frontal analysis continuous capillary electrophoresis (FACCE) $(11,12)$, has been developed for the study of protein-polyelectrolyte (PE) binding.

Because both biological and synthetic polyelectrolytes have contour lengths that are large compared to the polyelectrolyte-binding sites on the protein surface, it is necessary to view the protein in these cases as the ligand, one polyelectrolyte capable of binding a number of proteins. There is no fundamental problem in discriminating between bound and free proteins, and there is a sound theoretical framework for the analysis of such macromolecular binding (13). Experimentally, the binding of proteins to linear macromolecules has been studied by turbidimetry, light scattering, electrophoretic mobility, viscometry, fluorescence, potentiometric titration, and dialysis equilibrium (14). However, only the last directly yields binding isotherms, and it is unacceptably slow. Thus, FACCE addresses the need for rapid and precise determination of such binding isotherms.

In contrast to conventional frontal chromatography (CFC), FACCE combines continuous sampling, integrating sample injection and separation into one process as illustrated in Fig. 1. The electroosmotic flow that transports all components toward the cathode arises from the negatively charged wall of the fused-silica capillary. CFC employs regular chromatography methods but with a sample volume relatively large compared to the capacity of the separation column. Careful selection of the amount of sample injected, the flow rate of the mobile phase, and the length of the separation column, leads to continuous but distinct plateaus, followed by resumption of detector baseline response as shown in the electropherograms in Fig. 1A. In FACCE, the capillary is filled and equilibrated with the run buffer prior to sample introduction. The inlet end of the capillary is then immersed in the sample vial and a voltage is applied across the capillary to initiate the sample introduction and separation process. Species separated by electrophoresis appear as discrete and progressive plateaus in the electropherograms as shown in Fig. 1B. The separation profile of FACCE is particularly suitable for the study of binding in systems with rapid binding kinetics, inasmuch as it allows for the determination of the concentrations of free or bound ligands without complete separation avoiding perturbation of the binding equilibrium.

FACCE is particularly effective in multiple complexation equilibria where more than one protein binds to a single ligand; measurement of the concentration of free ligand is determined not from mobility but from the peak height which directly indicates the free protein concentration. The stoichiometric relationship between bound protein and the protein-ligand complex can then be fit to appropriate binding isotherms to yield binding constants and the bind- 

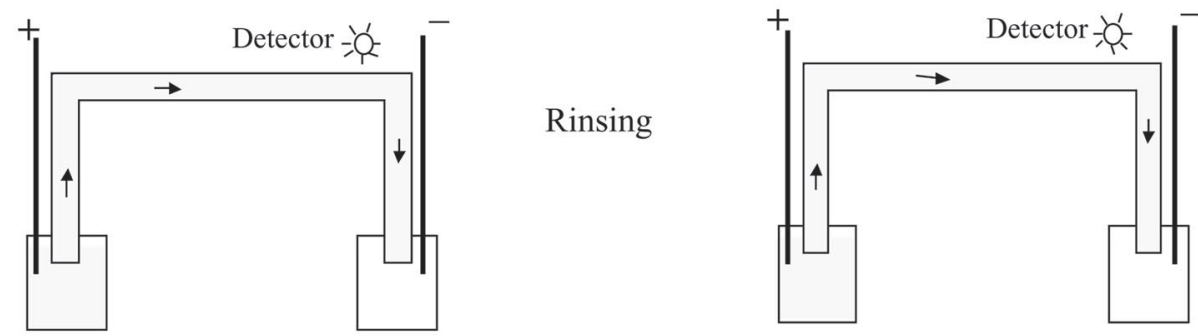

Buffer

Waste

Buffer

Waste
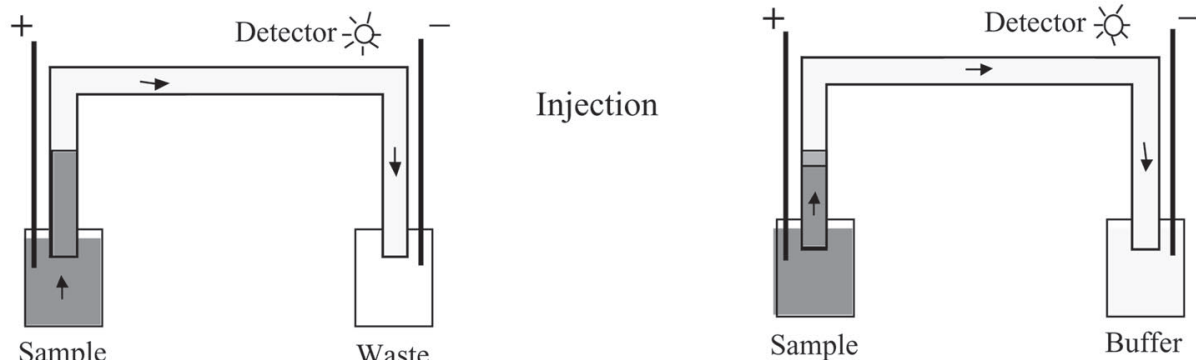

Waste

Injection
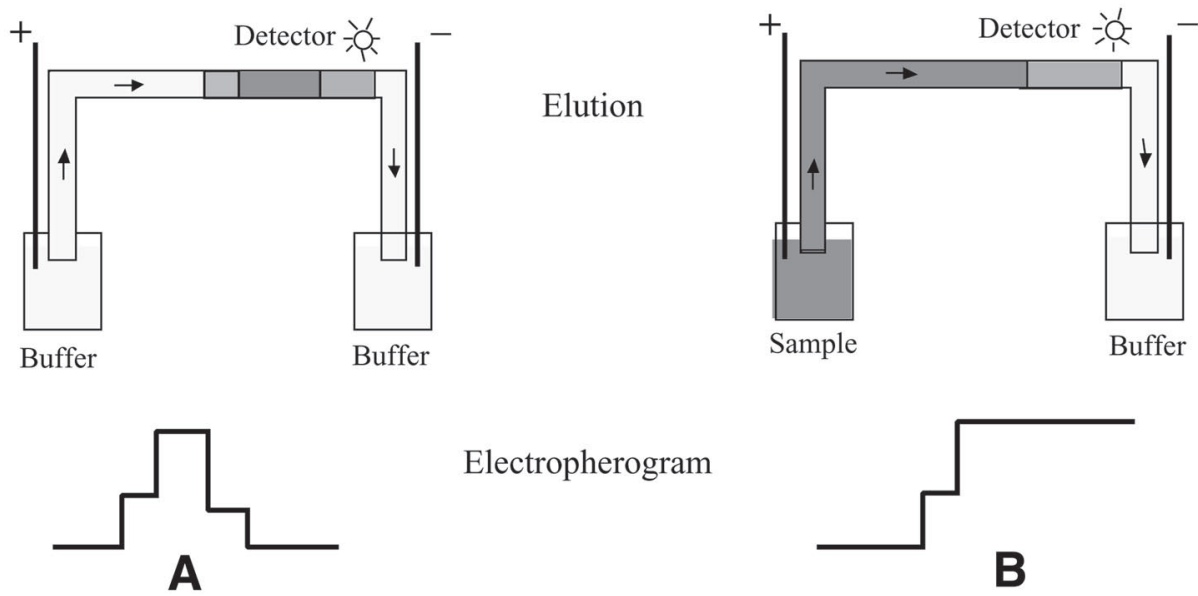

Electropherogram

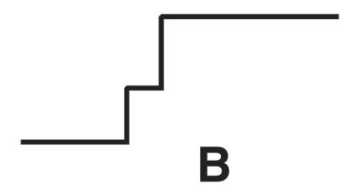

Fig. 1. Schematics of CFC (A) and FACCE (B). Reprinted with permission from ref. 12 .

ing-site size, both of which are parameters essential to the elucidation of the binding mechanism. Binding of proteins with both synthetic and biological polyelectrolytes is an example of multiple complexation and has, therefore, been studied with FACCE (11-25). In this paper, analysis by FACCE of the binding of bovine serum albumin (BSA) and heparin will be discussed as an example. Because heparin is a negatively charged polyelectrolyte, it interacts 
with the positive charges on the protein. The positive charges of the protein increase with decreasing $\mathrm{pH}$, and the binding force increases. However, binding often occurs at $\mathrm{pH}$ above the isolecetric point $(\mathrm{p} I)$ of the protein where the protein bears the same net charge as the polyelectrolyte. For example, the $\mathrm{p} I$ of BSA is 4.9 and binding at $I=0.01 M$ occurs at $\mathrm{pH} 7.0$, where both the protein and the polymer bear net-negative charges. This is an indication of "patch binding" in which the electrostatic attraction between polyanion and a local protein positive region overcomes the repulsion between polyanion and the global protein charge (15).

Many functions have been ascribed to the interaction of heparin with various proteins (26). Although no specific function has been identified with the heparin-BSA interaction, this system has been used to develop the methodology that would enable application of the technique to, for example, heparinprotein cognate pairs, DNA-binding proteins, and other biological polyelectrolyte-protein systems. The extended use of FACCE to such proteinpolyelectrolyte systems will facilitate a better understanding of many biological phenomena.

\section{Materials}

1. Heparin (sodium salt, porcine intestinal mucosa, Calbiochem, La Jolla, CA, nominal $\left.M_{r} 13,500-15,000\right)$.

2. BSA (fatty acid free, $M_{r} 68,000$, Boehringer Mannheim, Indianapolis, IN).

3. For turbidimetric titrations: Brinkmann PC800 probe colorimeter detecting at $420 \mathrm{~nm}$, equipped with a $1-\mathrm{cm}$ path-length fiber optics probe, and a $\mathrm{pH}$ meter.

4. FACCE rinsing and run buffer: phosphate buffer prepared at desired $\mathrm{pH}$ and ionic strength.

5. For FACCE rinsing: $1 N \mathrm{NaOH}$ before each use of capillary column, $0.1 \mathrm{~N} \mathrm{NaOH}$ for rinsing between consecutive runs.

6. FACCE instrument: P/ACE 5500 CE (Beckman, Fullerton, CA).

7. Fused-silica capillary of dimensions $50 \mu \mathrm{m} \times 27 \mathrm{~cm}$ (Polymicro Technologies Inc, Phoenix, AZ).

8. Milli-Q water for all buffer and solution preparations (Millipore, Milford, MA).

9. All protein and PE solutions should be prepared fresh, and complete solubilization should be achieved prior to experiments.

\section{Methods}

\subsection{Identification of Soluble Complex Region for Protein-Polyelectrolyte System}

Binding equilibria in any protein-PE system can only be studied under conditions corresponding to the formation of the complex without second-order reactions, such as aggregation or phase separation. Any protein-PE system can be identified in terms of one of these three states. For a polyanion-protein system at fixed ionic strength, the system progresses, upon decrease in $\mathrm{pH}$, 
from: (a) noninteracting solution, to (b) soluble complex phase, and finally to (c) complex aggregate or biphasic state (27-29). Turbidity is sufficiently sensitive to detect the two relevant transitions; therefore, these three regions can be effectively identified by $\mathrm{pH}$-turbidimetric titration. Titrations should be done at various ionic strengths to enable construction of a phase boundary: a plot of transition $\mathrm{pH}$ vs ionic strength, which shows the three regions corresponding to (a), (b), and (c) states. This will allow for determination of the working conditions for FACCE experiments, where the $\mathrm{pH}$ and ionic strength of the solution should lie in the complex formation region (b).

\subsubsection{Preparation of Protein-Polyelectrolyte Solutions for $\mathrm{pH}$-Turbidimetric Titration}

1. The concentrations of protein and PE solutions to be prepared should be determined such that protein is in excess when they are mixed. A weight ratio of protein to PE of 10 would be appropriate for a typical titration.

2. Dissolve the protein and PE separately in desired salt solution.

3. Mix appropriate amounts of protein and PE solutions to achieve the mixture with the desired weight ratio.

4. Prepare a blank protein solution for blank titration that has the protein concentration in the mixture.

5. Add $1 M \mathrm{NaOH}$ gradually to the mixture to adjust the $\mathrm{pH}$ to 10.0 .

6. As an example, $4 \mathrm{mg} / \mathrm{mL}$ of BSA and $0.4 \mathrm{mg} / \mathrm{mL}$ of heparin solutions were prepared in $0.01 \mathrm{M} \mathrm{NaCl}$ solution, and $10 \mathrm{~mL}$ of both were combined to obtain a final mixture with weight ratio of 10 , making a total volume of $20 \mathrm{~mL}$. (The required amount of sample volume depends on the size of the probe and the container.) A "blank" protein solution was $4 \mathrm{mg} / \mathrm{mL}$ BSA in the same $\mathrm{NaCl}$ solution.

\subsection{2. $\mathrm{pH}$-Turbidimetric Titration}

The soluble complex region lies between $\mathrm{pH}$ at the initial point of increasing turbidity $(\mathrm{pHc})$ and $\mathrm{pH}$ at the point of the abrupt increment of turbidity $(\mathrm{pH} \phi)$ $(14,15)$.

1. Titrate the protein-PE solution with $1 M \mathrm{HCl}$ using, e.g., Gilmont microburet, while monitoring simultaneously $\mathrm{pH}$ and $\%$ transmittance (\%T) at $420 \mathrm{~nm}$.

2. Plot $100-\% \mathrm{~T}$, proportional to turbidity vs $\mathrm{pH}$, and identify $\mathrm{pHc}$ and $\mathrm{pH} \phi$.

3. A sample plot for heparin and BSA at $I=0.01 \mathrm{M}$ is shown in Fig. 2. The soluble complex exists in region 2 which lies between $\mathrm{pHc}(7.1)$ and $\mathrm{pH} \phi(5.0)$.

\section{2. $C E$}

\subsubsection{Equipment}

$\mathrm{CE}$ is performed using a Beckman P/ACE $5500 \mathrm{CE}$ with programmatic autosampling. Operating temperature is at $25^{\circ} \mathrm{C}$. The dimensions of the fusedsilica capillary are $50 \mu \mathrm{m} \times 27 \mathrm{~cm}$ with an effective length (the distance from the inlet end to the UV detector) of $20 \mathrm{~cm}$. 


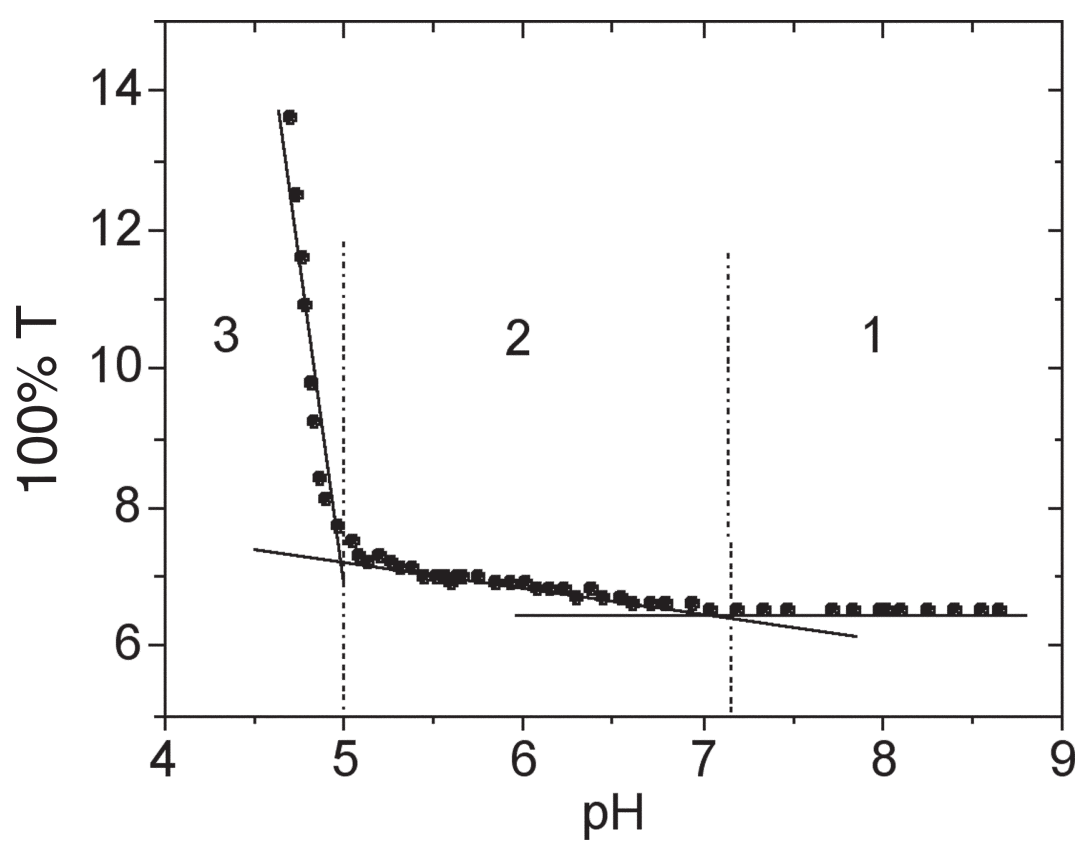

Fig. 2. Turbidimetric titration curve for $1 \mathrm{~g} / \mathrm{L} \mathrm{BSA}$ and $1 \mathrm{~g} / \mathrm{L}$ heparin at $I=0.01 M$, Region 1, no complex formation as turbidity does not change. Region 2, complex formation as turbidity starts to increase gradually. Region 3, phase separation as there is an abrupt change in turbidity. The dashed lines represent the defined $\mathrm{pHc}$ and $\mathrm{pH} \phi$ values dividing regions 1,2 , and 3 . Reprinted with permission from ref. 19.

\subsubsection{Procedure for FACCE}

Each measurement follows the procedure given below.

1. Wash the capillary with $0.1 \mathrm{M} \mathrm{NaOH}$ solution for $5 \mathrm{~min}$. (This rinsing is necessary between each run to remove any adsorbed protein on the capillary surface. See Note 1.)

2. Rinse the capillary with water for 5 min.

3. Run phosphate buffer solution of desired $\mathrm{pH}$ and ionic strength through the capillary for $5 \mathrm{~min}$.

4. Immerse the negative pole tip of the capillary into the sample and the positive pole tip into the buffer solution.

5. Apply a constant voltage and monitor UV absorbed spectra at a certain wavelength. The operating voltage and the wavelength should be determined so that the best resolution is obtained for the desired components to be measured. The typical applied voltage range is $5-15 \mathrm{kV}$. For most proteins, 200 or $214 \mathrm{~nm}$ would be the best detection wavelength.

6. As an example, the electropherograms shown in Fig. 3 was obtained by applying a voltage of $10 \mathrm{kV}$ at $214-\mathrm{nm}$ wavelength. 


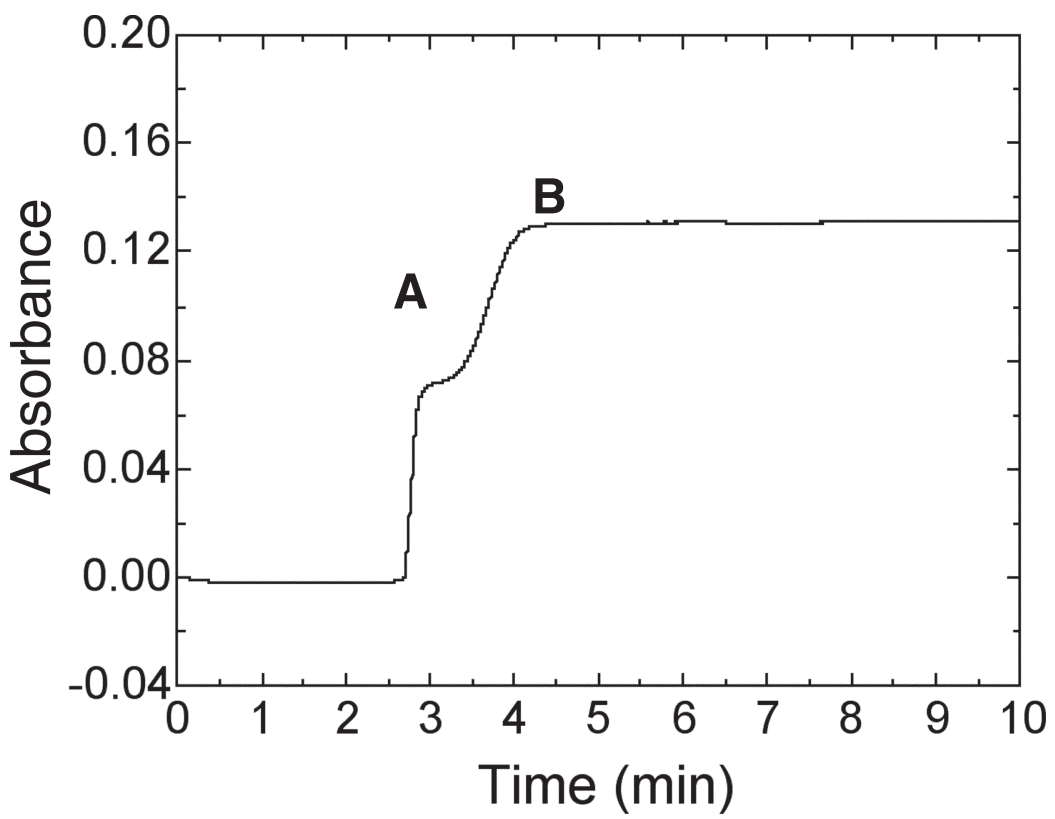

Fig. 3. Electropherogram of a sample FACCE experiment with BSA $(4 \mathrm{~g} / \mathrm{L})$ and heparin $(0.2 \mathrm{~g} / \mathrm{L})$ mixture at $\mathrm{pH}=6.8, I=0.01 \mathrm{M}$ with plateaus representing (a) free BSA, (b) BSA-heparin complex.

\subsection{Determination of Free-Protein Concentration}

The electropherogram of FACCE shows multiple plateaus, the number of which depends on the number of components in the mixture. In a protein-PE mixture, two plateaus are typically observed (see Fig. 3), the first plateau corresponding to free protein and the second to protein-PE complex. The concentration of free protein can be determined by the height of the first plateau using a calibration curve (12).

\subsubsection{Calibration Curve for Free Protein}

1. Solutions of protein from 0.1 to $1.5 \mathrm{mg} / \mathrm{mL}$ are prepared in $\mathrm{NaH}_{2} \mathrm{PO}_{4}-\mathrm{Na}_{2} \mathrm{HPO}_{4}$ buffer solution at the desired $\mathrm{pH}$ and ionic strength. Measure each sample solution as explained in Subheading 3.2.2.

2. Measure the height of the single plateau in the electropherogram at each concentration.

3. Plot absorbance (plateau height) vs concentration of protein. 


\subsubsection{Determination of Free Protein in a Protein-PE System}

1. Make up a series of solutions containing protein and PE dissolved in the appropriate buffer solution. The concentrations needed for the analysis depend on the strength of UV signal. For example, for BSA and heparin, the protein concentration was $0.4-4.0 \mathrm{~g} / \mathrm{L}$ with heparin at $0.2 \mathrm{~g} / \mathrm{L}$.

2. Measure each sample solution as explained in Subheading 3.2.2.

3. Determine the concentration of free protein by absorbance of first plateau height using the calibration curve (see Note 2).

\subsection{Data Analysis}

There are several procedures for fitting binding isotherm data $(30,31)$. Particularly appropriate in the present case is the one based on a binding theory of large ligands to a 1D homogeneous lattice given by McGhee and von-Hippel $(32,33)$. This is appropriate for specific or nonspecific binding involving cooperative or noncooperative interaction between binding sites.

\subsubsection{Constructing the Binding Isotherm}

The binding isotherms were obtained by plotting the concentration of free protein, $L_{\text {free }}$, which is calculated as explained above vs the average number of bound protein per unit charged group on heparin, $v$ (see Note 3) and (Fig. 4).

\subsubsection{Determination of Binding Parameters Via McGhee and von-Hippel Equation}

General equation for McGhee and von Hippel model (31) is given in Eq. 1:

$$
\frac{v}{L_{\text {free }}}=\mathrm{K}_{\mathrm{b}}(1-n v)\left[\frac{(2 w+1)(1-n v)+v-R}{2(w-1)(1-n v)}\right]^{n-1} \times\left[\frac{1-(n+1) v+R}{2(1-n v)}\right]^{2}
$$

with

$$
R=\sqrt{[1-(n+1) v]^{2}+4 w v(1-n v)}
$$

where $v$ represents the binding density (in units of moles of bound ligand per mole of total lattice residue), $L_{\text {free }}$ is the free-ligand concentration, $K_{b}$ is the binding constant, $n$ is the number of binding sites, and $w$ is the cooperativity parameter.

For $w=1$, which is the case for noncooperative binding, Eq. 1 reduces to Eq. 3 for noninteracting ligands. In the case of BSA-heparin, Eq. 3 was used for analysis of binding parameter as no additional cooperativity term was needed to obtain a good fit to the binding isotherms. 


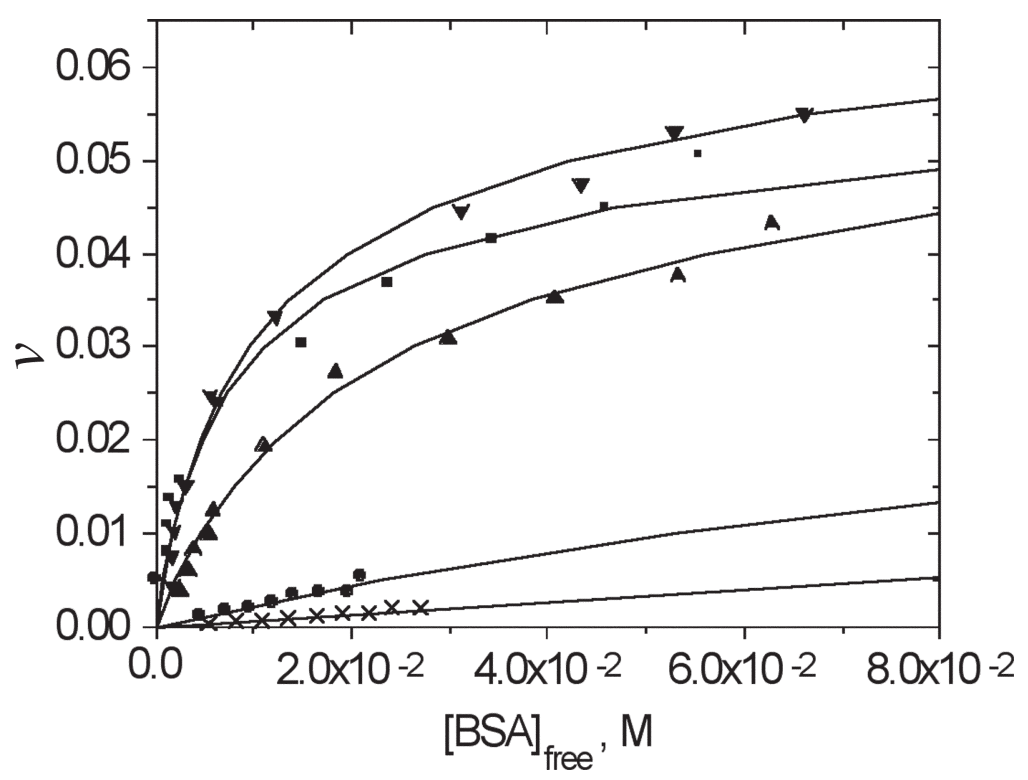

Fig. 4. Binding isotherms for BSA and heparin at ionic strengths of $(\boldsymbol{\nabla}) 2 \mathrm{~m} M$, $7 \mathrm{~m} M,(\Delta) 10 \mathrm{~m} M,(\bullet) 30 \mathrm{mM},(\times) 50 \mathrm{~m} M$ in phosphate buffer at $\mathrm{pH}=6.8$; the solid lines are fits to the McGhee von Hippel equation (from ref. 19).

$$
\frac{v}{L_{\text {free }}}=\mathrm{K}_{\mathrm{b}}(1-n v)\left[\frac{1-n v}{1-(n-1) v}\right]^{n-1}
$$

Equation 3 yields two parameters, the intrinsic binding constant $\mathrm{K}_{\mathrm{b}}$ and the binding-site size $n$. The binding isotherms are fitted to Eq. 3 where $v$ is the number of bound BSA per ionic site of heparin, $L_{\text {free }}$ is the concentration of free BSA, $\mathrm{K}_{\mathrm{obs}}$ is the observed binding constant, and $n$ is the binding site size in number of heparin charge groups (see Note 3). The nonlinear curve fitting can be carried out by a software such as Origin (Microcal Software, Inc.) to obtain the parameters $\mathrm{K}_{\mathrm{obs}}$ and $n$. The fitted curves are also shown in Fig. 4 for $\mathrm{BSA}$ and heparin at various ionic strengths. The calculated parameters are given in Table 1.

\section{Notes}

1. The adsorption of protein on the capillary wall is a significant problem. In case of BSA, strong adsorption of protein was observed at $\mathrm{pH}<6.5$; therefore, the measurements were made above this $\mathrm{pH}$. The adsorption conditions which may differ for each protein may require the use of a coated capillary. 
Table 1

Binding Constants and Binding Site Size for BSA-Heparin Interaction Calculated by Nonlinear Curve Fitting of Fig. 4 Data to Eq. 3

\begin{tabular}{lcc}
\hline Ionic strength $(M)$ & $\log K$ & $\mathrm{n}( \pm 0.8)$ \\
\hline 0.05 & 1.88 & 12.7 \\
0.03 & 2.39 & 13 \\
0.01 & 3.44 & 11.4 \\
0.007 & 3.89 & 12.9 \\
0.002 & 3.85 & 10.8 \\
\hline
\end{tabular}

2. A typical FACCE electropherogram shows two steps; however, more have also been observed (28). In addition, in some cases, the electropherogram had a spike peak before the first plateau (34), which may arise from adsorption of protein onto the capillary wall. Although this behavior did not significantly affect determination of free BSA here, the use of a coated capillary might be necessary to reduce adsorption when the effect becomes more significant.

3. Binding density $v$ is calculated by dividing the bound protein concentration (in $\mathrm{mol} / \mathrm{L}$ ) by the charge of heparin (in eq.mol/L). Because heparin has an equivalent weight of $200 \mathrm{~g} / \mathrm{mol}$, a $0.2 \mathrm{~g} / \mathrm{L}$ heparin solution contains $1.0 \times 10^{-3}$ eq. $\mathrm{mol} / \mathrm{L}$. Binding density $v$ is defined in this manner because the binding site on heparin does not correspond to a well-defined portion of molecule, which is the typical case for nonspecific binding arising from long range electrostatic forces. The size of the apparent binding site $n$ is defined for the same reason in terms of the number of charges it encompasses. An estimate of the number of disaccharide units involved in binding can easily be obtained by dividing $n$ by the average number of charges of one disaccharide, 3.7 for heparin (15). The length of the binding site can then be calculated from the length of a disaccharide unit, $11 \AA$.

\section{Acknowledgment}

Paul L. Dubin acknowledges the support of NSF grant CHE 9987891.

\section{References}

1. Kraak, J. C., Busch, S., and Poppe, H. (1992) Study of protein-drug binding using capillary elecrophoresis. J. Chromatogr. 608, 257-264.

2. Ohara, T., Shibukawa, A., and Nakagawa, T. (1992) Capillary electrophoresis/ frontal analysis for microanalysis of enantioselective protein binding of a basic drug. Anal. Chem. 67, 3520-3525.

3. Oravcova, J., Sojkova, D., and Linder, W. (1996) Comparison of the HummelDreyer method in high-performance liquid chromatography and capillary electrophoresis conditions for study of the interaction of (RS)-, (R)- and (S)-carvedilol with isolated plasma proteins. J. Chromatogr. B. 682, 349-357. 
4. Chu, Y. H. and Whitesides, G. M. (1992) Affinity capillary electrophoresis can simultaneously measure binding constants of multiple peptides to vancomycin. J. Org. Chem. 57, 3524-3526.

5. Heegard, N. H. H. and Robey, F. A. (1993) Capillary electrophoresis-based assay for the binding of $\mathrm{Ca}^{2+}$ and phosphorylcholine to human C-reactive protein. $J$. Immun. Met. 166, 103-110.

6. Kajiwara, H., Hirano, H., and Oono, K. (1991) Binding shift assay of parvalbumin, calmodulin and carbonic anhydrase by high-performance capillary electrophoresis. J. Biochem. Biophys. Meth. 22, 263-268.

7. Honda, H., Taga, A., Suzuki, K, Suzuki, and S., Kakehi, K. (1992) Determination of the association constant of monovalent mode protein-sugar interaction by capillary zone electrophoresis. J. Chromatogr. 597, 377-382.

8. Takeda, K., Sasaoka, H., Sasa, K., Hirai, H., Hachiya, K., and Moriyama, Y. (1992) Size and mobility of sodium dodecyl sulfate-bovine serum albumin complex as studied by dynamic light scattering and electrophoretic light scattering. $J$. Coll. Int. Sci. 154, 385-392.

9. Karim, M.R., Shinagawa, and S., Takagi, T. (1994) Electrophoretic mobilities of the complexes between sodium dodecyl sulfate and various peptides or proteins determined by free solution electrophoresis using coated capillaries. Ectrophoresis. 15, 1141-1146.

10. Chu, Y. H., Lees, W. J., Stassinopoulos, A, and Walsh C. T. (1994) Using affinity capillary electrophoresis to determine binding stoichiometries of protein-ligand interactions. Biochem. 33, 10,616-10,621.

11. Gao, J. Y. (1998) Binding of proteins to polyelectrolytes studied by capillary electrophoresis. Ph.D. thesis, Chemistry, Indiana University-Purdue University, Indianapolis.

12. Gao, J. Y., Dubin, P. L., and Muhoberac, B. B. (1997) Measurement of the binding of proteins to polyelectrolytes by frontal analysis continuous capillary electrophoresis. Anal. Chem. 69, 2945-2951.

13. Clore, G. M., Gronenborn, A. M., and Davies, R.W. (1982) Theoretical aspects of specific and non-specific equilibrium binding of proteins to DNA as studied by the nitrocellulose filter binding assay. Co-operative and non-co-operative binding to a one-dimensional lattice. J. Mol. Biol. 155, 447-466.

14. Xia, J. and Dubin, P. L. (1994) Protein-polyelectrolyte complexes, in Macromolecular Complexes in Chemistry and Biology, (Dubin, P. L., et al., eds.) Springer-Verlag, New York, NY, pp. 247-271.

15. Hattori, T., Hallberg, R. K., and Dubin, P. L. (2000) Roles of electrostatic interaction and polymer structure in the binding of $\beta$-lactoglobulin to anionic polyelectrolytes: Measurement of binding constants by frontal analysis continuous capillary electrophoresis. Langmuir 16, 9738-9743.

16. Kimura, K., Seyrek, E., and Dubin, P. L. (2001) Binding of bovine serum albumin to heparin determined by turbidimetric titration and frontal analysis continuous capillary electrophoresis. Anal. Chem. 295, 158-167. 
17. Hattori, T., Kimura, K., Seyrek, E., and Dubin, P. L. (2001) The use of frontal analysis continuous capillary electrophoresis to compare protein binding by natural and synthetic polyelectrolyte. Analyt. Sci. (Japan) 17, 93-95.

18. Gao, J. Y. and Dubin, P. L. (1999) Binding of proteins to copolymers of varying hydrophobicity. Biopolymers 49, 185-193.

19. Seyrek E., Dubin, P. L., Tribet, C., and Gamble, E.A. (2003) Ionic strength dependence of protein-polyelectrolyte interactions. Biomacromolecules 4, 273-282.

20. Hallberg, R. K. and Dubin, P. L. (1998) Effect of pH on the binding of b-lactoglobulin to sodium polystyrenesulfonate. J. Phys. Chem. B 102, 8629-8633.

21. Porcar, I., Cottet, H., Gareil, P., and Tribet, C. (1999), Association between protein particles and long amphiphilic polymers: effect of the polymer hydrophobicity on binding isotherms. Macromolecules 32, 3922-3929.

22. Porcar, I., Gareil, P., and Tribet, C. (1998) Formation of complexes between protein particles and long amphiphilic polymers: binding isotherms versus size and surface of the particles. J.Phys. Chem. B. 102, 7906-7909.

23. Ladaviere, C., Lorenzo, C., Elaissari, A., Mandrand, B., and Delair, T. (2000) Electrostatically driven immobilization of peptides onto (maleic anhydride-alt-methyl vinyl ether) copolymers in aqueous media. Bioconjugate Chem. 11, 146-152.

24. Tanaka, Y. and Terabe, S. (2002) Estimation of binding constants by capillary electrophoresis. J. Chromatog. B. 768, 81-92.

25. Rundlett, K. L. and Armstrong, D. W. Methods for the determination of binding constants by capillary electrophoresis. Electrophoresis. 22, 1419-1427.

26. Conrad, H. E. (1998) Heparin-Binding Proteins. Academic, San Diego, CA.

27. Mattison, K. W., Yingfan, W., Grymonpré, K., and Dubin, P. L. (1999) Microand macro-phase behavior in protein-polyelectrolyte complexes. Macromol. Symp. 140, 53-76.

28. Park, J. M., Muhoberac, B. B., Dubin, P. L., and Xia, J. (1992) Effect of protein charge heterogeneity in protein-polyelectrolyte complexation. Macromolecules 25, 290-295.

29. Mattison, K. W., Brittain, I. J., and Dubin, P. L. (1995) Protein-polyelectrolyte phase boundaries. Biotech. Prog. 11, 632-637.

30. Scatchard, G. (1949) The attraction of proteins for small molecules and ions. Ann. N.Y. Acad. Sci. 51, 660-672.

31. Heck, H. D. (1971) Statistical theory of cooperative binding to proteins, the Hill equation and the binding potential. J. Am. Chem. Soc. 93, 23-29.

32. McGhee J. D. and von Hippel P. H. (1974) Theoretical aspects on DNA-protein interactions: co-operative and non-co-operative binding of large ligands to a onedimensional homogeneous lattice. J. Mol. Biol. 86, 469-489.

33. Olson, S. T., Halvorson, H. R., and Björk I. (1991) Quantitative characterization of the thrombin-heparin interaction. J. Biol. Chem. 266, 6342-6352.

34. Gao, J. Y., Dubin, P. L., and Muhoberac, B. B. (1998) Capillary electrophoresis and dynamic light scattering studies of structure and binding characteristics of protein-polyelectrolyte complexes. J. Phys. Chem. B. 102, 5529-5535. 